\title{
Reputação corporativa e oportunidade de crescimento
}

\section{Corporate reputation and opportunity for growth}

\author{
ALAN DIÓGENES GÓIS* \\ MÁRCIA MARTINS MENDES DE LUCA** \\ NATHÁLIA MELO SOUSA**
}

\section{RESUMO}

O estudo tem por objetivo investigar a relação entre a reputação corporativa e a oportunidade de crescimento das empresas listadas na BM\&FBovespa. Trata-se de uma pesquisa descritiva, com abordagem quantitativa dos dados de 230 empresas coletados no Formulário de Referência, no Balanço Patrimonial, no Estatuto Social, no ranking Proprietários do Brasil e na base de dados do Economatica ${ }^{\circledR}$. Os resultados evidenciaram que a reputação do acionista majoritário, a reputação do diretor executivo e a governança corporativa formam o fator reputação corporativa, o qual influencia positivamente a oportunidade de crescimento, maximizando o valor da empresa. Verificou-se ainda a existência de relação entre a oportunidade de crescimento e as variáveis desempenho empresarial, endividamento, crescimento em vendas e tamanho da empresa. Conclui-se que a reputação, considerando a perspectiva da governança corporativa, auxilia na redução dos custos de transação e na maximização do valor de mercado das companhias abertas, uma vez que é considerada um ativo que as

* Universidade de São Paulo. Doutorando em Controladoria e Contabilidade pela Universidade de São Paulo; Mestre em Administração e Controladoria pela Universidade Federal do Ceará; Bacharel em Ciências Contábeis pela Universidade Federal do Ceará. O autor agradece o apoio da Fundação de Amparo à Pesquisa do Estado de São Paulo (FAPESP), processo 2016/10738-5. alandgois@hotmail.com

** Universidade Federal do Ceará. Doutora e Mestre em Controladoria e Contabilidade pela Universidade de São Paulo; Bacharel em Ciências Contábeis pela Universidade de Fortaleza. Professora Associada da Universidade Federal do Ceará. marciadeluca@ufc.br

*** Universidade Federal do Ceará. Bacharel em Ciências Contábeis pela Universidade Federal do Ceará. nathaliamsousa@hotmail.com 
empresas conseguem obter junto aos stakeholders e tem como características o diferencial competitivo e a vantagem competitiva. Palavras-chave: Reputação do acionista majoritário; reputação do diretor executivo; governança corporativa; reputação corporativa; oportunidade de crescimento.

\section{Abstract}

The study aims at examining the association between corporate reputation and opportunity for growth in firms traded on BM\&FBovespa. In this descriptive and quantitative, information on 230 firms was retrieved from reference forms, balance sheets, by-laws, the 'Proprietários do Brasil' ranking, and the Economatica ${ }^{\circledR}$ system. Our results show that corporate reputation is a product of the reputation of the majority shareholder, the reputation of the CEO and corporate governance, with a positive impact on opportunity for growth and market value. In addition, associations were found between opportunity for growth and the variables 'corporate performance', 'indebtedness', 'growth in sales' and 'company size'. From the perspective of corporate governance, it may be concluded that, as a stakeholder-supported asset and a competitive differential/advantage, corporate reputation reduces transaction costs and boosts the market value of public firms.

Keywords: Reputation of the majority shareholder; reputation of the CEO; corporate governance; corporate reputation; opportunity for growth.

\section{INTRODUÇÃo}

A reputação corporativa se apresenta como um diferencial competitivo a ser obtido pela empresa junto aos seus stakeholders (BALMER; GREYSER, 2006), e, ainda, como fator que busca maximizar o valor da empresa (FOMBRUN; SHANLEY, 1990; VAN RIEL; FOMBRUN, 2007; COLE, 2012). Zabala et al. (2005) definem a boa reputação como o reconhecimento, pelos stakeholders, de que uma empresa executa as melhores práticas em sua gestão de recursos. Para tanto, dentre outros aspectos, destaca-se que esse reconhecimento somente é possível em um ambiente com reduzida assimetria informacional (YOON; GUFFEY; KIJEWSKI, 1993) e baixo risco, em que os atores da gestão e do controle das empresas desempenham papel fundamental. 
A redução de riscos no relacionamento entre esses atores implica uma diminuição nos custos de transação, representando um elemento de eficiência na competitividade das empresas. De acordo com Soares (2008), a existência dos custos de transação deve-se a dois pressupostos comportamentais, abordados pela Teoria da Economia dos Custos de Transação (ECT): racionalidade limitada e oportunismo dos agentes.

Por sua vez, a reputação, tanto dos atores quanto da empresa, tende a atenuar os incentivos para um comportamento oportunístico e reduzir os custos de transação associados à racionalidade limitada, implícitos nos custos globais de procura e seleção de parceiros (CHILES; McMACKIN, 1996; BROMLEY, 2001). Levando-se em conta os preceitos da ECT, pode-se afirmar que tanto os diretores executivos como os acionistas majoritários possuem racionalidade limitada e podem adotar ações oportunísticas, na medida em que os diretores executivos podem não alinhar os seus interesses com os dos acionistas e que os acionistas majoritários podem expropriar os direitos dos acionistas minoritários, aumentando os custos de transação. Dessa forma, as empresas precisam coordenar as ações dos indivíduos para tentar reduzir os custos de transação, impulsionando a adoção de melhores práticas de governança corporativa como fiscalizadora dos pressupostos comportamentais dos gestores e dos acionistas (PERES, 2007; SILVA JÚNIOR; SILVA; SILVA, 2013), e obter vantagem competitiva.

Cabe destacar que a adoção de melhores práticas de governança corporativa pode ser entendida como uma resposta às demandas do mercado por igualdade no tratamento dos acionistas, transparência na prestação de contas pelos gestores e responsabilidade corporativa (OLIVEIRA et al., 2013). A adoção de boas práticas de governança corporativa reduz a assimetria informacional e os riscos entre os agentes e gera mais credibilidade junto aos stakeholders, contribuindo para a maximização do valor da organização, bem como para a sua continuidade (IBGC, 2009).

Destarte, a reputação do diretor executivo e do acionista majoritário e a governança corporativa tendem a mitigar problemas com oportunismo e racionalidade limitada; quanto maior a presença de tais características nas empresas, maior é a sua reputação corpora- 
tiva, uma vez que se transmite mais confiança aos stakeholders. Essa reputação corporativa, como versa Robert e Dowling (2002), gera vantagem competitiva e desempenho superior devido à oportunidade de crescimento que essas empresas enfrentam.

Nesse contexto, a questão de pesquisa que se procura responder é: qual é a relação entre a reputação corporativa e a oportunidade de crescimento das empresas listadas na Bolsa de Valores, Mercadorias e Futuros (BM\&FBovespa)? Para tanto, o objetivo geral do presente estudo consiste em investigar a relação entre a reputação corporativa e a oportunidade de crescimento das empresas listadas na BM\&FBovespa.

A pesquisa reúne os dados de 230 empresas listadas na BM\&FBovespa, na posição de 22/11/2015, coletados no Formulário de Referência e nas Demonstrações Financeiras Padronizadas (Balanço Patrimonial) referentes ao exercício de 2013, disponíveis no website da BM\&FBovespa, além das informações consignadas no Estatuto Social, disponível no website institucional de cada empresa, e no ranking Proprietários do Brasil (INSTITUTO MAIS; EITA, 2014). Os dados financeiros referentes a 2014 foram levantados no banco de dados Economatica ${ }^{\circledR}$. Frisa-se que o estudo adota a defasagem temporal entre a reputação corporativa e a oportunidade de crescimento, aplicando-se a análise fatorial e a regressão linear múltipla para obtenção de resultados.

Considerando-se que a reputação corporativa vem sendo bastante debatida nos meios empresarial e acadêmico, haja vista a crescente competitividade e o aumento da oferta de serviços e produtos, ocasionados pela globalização, entende-se oportuna a análise da reputação como fator distintivo e de fundamental relevância para investidores, que buscam proteção contra possíveis custos de transação ocasionados pelo comportamento oportunístico ou associado à racionalidade limitada dos gestores. Destaca-se, ainda, que o estudo se diferencia por abordar a reputação pessoal de gestores e acionistas majoritários e sua influência nas práticas de governança corporativa e na oportunidade de crescimento das empresas.

\section{REFERENCIAL TEÓRICO}

A ECT parte de dois pressupostos comportamentais: os indivíduos são oportunistas; e há limites em sua capacidade cognitiva 
para processar a informação disponível, também chamada de racionalidade limitada (SOARES, 2008). O oportunismo aponta que os agentes são autointeressados e podem, se for do interesse deles, trapacear, mentir ou quebrar promessas (AZEVEDO, 2000). Já a racionalidade limitada deriva da noção de incompletude contratual; ou seja, devido aos limites cognitivos dos agentes, não é possível o estabelecimento de contratos que deem conta de todas as contingências futuras (AZEVEDO, 2000). Segundo Williamson (1996), a racionalidade limitada e o oportunismo são os maiores problemas nas organizações econômicas complexas.

Para atenuar os custos de transação decorrentes desses pressupostos comportamentais, faz-se necessária a construção de mecanismos que, no presente estudo, são representados pela reputação (WILLIAMSON, 1996) e pela governança corporativa (BERGH et al., 2010; SILVEIRA, 2004).

No contexto da presente pesquisa, a reputação é um mecanismo que pode minimizar os custos de transação, na medida em que maior reputação dos atores corporativos sugere menos dispêndio de recursos para reduzir ações oportunísticas (KARUNA, 2009). Bromley (2001) define reputação como a distribuição de opiniões sobre uma pessoa ou outra entidade, por parte dos stakeholders; destarte, pessoas e empresas estão sujeitas a determinada reputação.

Cruz e Lima (2010) definem reputação corporativa como o resultado das interações repetidas e de experiências acumuladas nos diversos níveis de relacionamento da organização. Pode-se pressupor que a repetição de comportamentos da organização gera uma expectativa de continuidade para os stakeholders, interpretando-a também como oportunidade de crescimento e de vantagem competitiva da empresa em relação às demais. Corroborando essa definição, Brammer, Millington e Pavelin (2009) afirmam que a reputação de uma empresa pode ser determinada segundo as interpretações do público em geral sobre as informações publicadas pela própria empresa ou em meios de comunicação.

Segundo Machado Filho e Zylbersztajn (2004), a reputação corporativa é como os stakeholders veem a empresa, de forma positiva ou negativa; essa percepção pode surgir dos comportamentos dela em suas relações com o meio interno e o externo. Organizações com 
boa reputação conseguem se manter em boas posições de mercado em relação às demais, garantindo uma vantagem competitiva. A reputação corporativa é fundamentada nas relações comerciais passadas das empresas; com isso, os diversos usuários podem prever possíveis condutas delas em eventos futuros; ou seja, o passado endossa o futuro (ROBERTS; DOWLING, 2002), justificando-se, assim, a utilização da defasagem temporal nos estudos que envolvem a temática reputação.

Alsop (2006) expõe que uma pesquisa realizada pela empresa Burson-Marsteller, em 2003, constatou que os entrevistados acreditam que metade da reputação corporativa de uma empresa é atribuível à reputação do diretor-executivo. Logo, pode-se entender que as características e implicações da reputação corporativa decorrem da reputação do diretor-executivo, por exemplo, ou de uma reputação pessoal (MEN, 2012).

Laird et al. (2013) conceituam reputação pessoal como uma identidade formada a partir da percepção dos demais, e que representa a combinação das características pessoais, revelações e comportamento demonstrados em determinado período. Segundo Alsop (2006), a reputação pessoal tem influência significativa nas decisões econômicas e financeiras e no valor de mercado das ações; logo, para manter níveis favoráveis de reputação corporativa, a organização precisa ter pessoas (diretor-executivo e acionista majoritário) com reconhecimento no mercado. $\mathrm{O}$ diretor-executivo e o acionista majoritário são representantes da empresa, na medida em que o primeiro possui o poder, e o segundo detém o controle e, internamente, coordenam e incentivam (especialmente o diretor-executivo) os empregados por meio de sua liderança e poder (KARUNA, 2009; MEN, 2012).

De acordo com Niap e Taylor (2012), a reputação de um diretor-executivo é construída levando-se em conta não apenas o valor e o desempenho da companhia, mas também qualidades como honestidade e credibilidade, bem assim um histórico de realizações, como a experiência na condução de grandes negócios e o comportamento íntegro; ou seja, ele deve ser eficaz em suas decisões, em vez de politicamente conveniente, alinhando os interesses dos acionistas com os da gestão. Tais características também se aplicam na atribuição 
da reputação pessoal ao acionista majoritário, levando-se em conta o seu papel no contexto empresarial.

Karuna (2009) apresenta duas consequências da relação entre boa reputação da gestão e custos de transação. A primeira possibilidade dessa relação é que quanto mais alta for a reputação do diretor-executivo, menor será a probabilidade de ele se envolver em ações que possam comprometer sua imagem, diminuindo, com isso, os custos de transação. A segunda é que o diretor-executivo com alto reconhecimento poderá manipular resultados e superavaliar os retornos dos investimentos, já que ele se sente pressionado para manter o alto nível de reputação. Em consequência, mesmo com diretores-executivos e acionistas majoritários com boa reputação, é necessário possuir e/ou manter fortes mecanismos de governança.

Dessa forma, a governança corporativa também se caracteriza como importante mecanismo, que permite, entre outras possibilidades, mitigar a assimetria informacional e o oportunismo dos agentes (PERES, 2007; SILVA JÚNIOR; SILVA; SILVA, 2013). Nesse contexto, Maia, Vasconcelos e De Luca (2013) exemplificam fatores a serem considerados nesse mecanismo, tais como: (i) política de divulgação de informações, (ii) código de conduta, (iii) política sobre contribuições e doações e (iv) política de combate a atos ilícitos. Esses fatores asseguram mais retornos sobre os investimentos, haja vista que reduzem os custos de transação e a assimetria informacional, logo, tornando a organização mais atraente para os investidores. Assim, ao remunerar os investidores da empresa, o administrador o faz para garantir vantagem competitiva, reduzir o risco em suas operações e manter uma boa reputação, com o intuito de conseguir novos financiadores (PEIXE, 2003).

A governança corporativa é considerada uma possível solução para os conflitos entre os gestores e os acionistas majoritários. Essa dualidade surge a partir do momento em que o controle e a propriedade da firma estão em mãos distintas, havendo uma divergência de interesses, em que o acionista procura maximizar sua riqueza e o outro (gestor) maximiza interesses pessoais (LA PORTA; LOPEZ-DE-SILANES; SHLEIFER, 1999). No Brasil, em decorrência da alta concentração de propriedade especialmente com direito a voto, o conflito mais frequente ocorre entre acionista controlador e acionista 
minoritário, em que o primeiro expropria os direitos do segundo (ALMEIDA; KLOTZLE; PINTO, 2013; CAIXE; MATIAS; OLIVEIRA, 2013).

Percebe-se, portanto, que o mecanismo de governança corporativa tem por objetivos: desenvolver um ambiente de mais segurança e confiabilidade dos atos e práticas administrativos com a finalidade de reduzir riscos; otimizar o valor da empresa; gerar oportunidade de crescimento; proteger investidores, empregados e credores; facilitar o acesso às informações, reduzindo a assimetria informacional; e alinhar os interesses de gestores e acionistas, majoritários e minoritários, pois, no Brasil, é comum o controle concentrado do capital (LA PORTA et al., 1998).

Cabe destacar que o advento de boas práticas de governança no meio corporativo promoveu substanciais mudanças no comportamento dos investidores, principalmente os que buscam benefícios no longo prazo, cujos efeitos de gestão repercutirão por um longo período no desempenho e no valor da organização (SILVEIRA, 2002; ANDRADE et al., 2009). Em unanimidade, especialistas apontam como causa de escândalos financeiros o resultado da deficiência ou ausência dos mecanismos de governança corporativa - é consenso que as fraudes financeiras ocasionam perdas significativas na avaliação dos investidores (FICH; SHIVDASANI, 2007). Dessa forma, empresas se preocupam em evidenciar suas práticas de governança, e alguns estudos apontam que a transparência da governança corporativa apresenta relação positiva com o valor e o desempenho da empresa (KAPPLER; LOVE, 2002; SILVEIRA, 2002; ANDRADE et al., 2009).

Pela ótica da ECT, Okimura (2003) define empresa como uma estrutura de governança capaz de minimizar os custos dos contratos derivados das ações oportunísticas dos agentes. Assim, ao adotar boas práticas de governança corporativa, ela oferece mais proteção aos investidores contra eventuais oportunismos, assegurando a maximização do seu valor (SILVEIRA, 2002; ANDRADE et al., 2009; SILVEIRA; BARROS; FAMÁ, 2003; SILVEIRA et al., 2010).

Ainda com relação à ECT e ao mecanismo reputação para redução dos custos dos contratos, Castro (2008) apresenta a reputação como fonte de vantagem competitiva a partir dos contratos tácitos que a organização desenvolve com quem estabelece relações comerciais. Destarte, de forma similar ao mecanismo governança, a reputação do diretor-executivo e do acionista majoritário (definida a partir de 
características pessoais) reduz os custos com monitoramento de possíveis ações oportunísticas, conforme apontado por Karuna (2009).

Pode-se afirmar, portanto, que por meio dos mecanismos reputação (diretor-executivo e acionista majoritário) e da governança corporativa, empresas elevam seus níveis de controle e monitoramento com vistas à redução dos custos de transação, de forma a atrair investimentos e maximizar a oportunidade de crescimento e valor, garantindo a sua continuidade. Segundo Cunha, Iara e Rech (2014, p. 17), "a maximização do valor de um negócio constitui-se como meta principal de gestão das empresas".

Com base no exposto, o estudo apresenta a seguinte hipótese de pesquisa:

$\mathrm{H}_{1}$ : Há relação positiva entre a reputação corporativa e a oportunidade de crescimento das empresas.

A partir dessa hipótese, fundamentada na literatura já mencionada, buscaram-se ainda, estudos empíricos que investigaram os construtos reputação corporativa e reputação pessoal, pois suas características e implicações são similares; governança corporativa; desempenho e valor das empresas. A Tabela 1 destaca alguns estudos empíricos nacionais e estrangeiros.

Tabela 1 - Estudos empíricos anteriores

\begin{tabular}{l|l|l}
\hline Autor & Relação & Resultado \\
\hline Fombrun e Shanley (1990) & Reputação corporativa e desempenho empresarial & Positivo \\
\hline Batistella et al. (2004) & Governança corporativa e desempenho empresarial & Negativo \\
\hline Rose e Thomsen (2004) & Reputação corporativa e valor de mercado & Indiferente \\
\hline Karuna (2009) & Reputação do diretor-executivo e governança corporativa & Negativo \\
\hline Macedo e Corrar (2012) & Governança corporativa e desempenho empresarial & Positivo \\
\hline Men (2012) & Reputação do diretor-executivo e reputação corporativa & Positivo \\
\hline Caixeta et al. (2011) & Reputação corporativa e desempenho empresarial & Negativo \\
\hline Niap e Taylor (2012) & Reputação do diretor-executivo e desempenho empresarial & Positivo \\
\hline Lee e Roh (2012) & Reputação corporativa e desempenho empresarial & Positivo \\
\hline Melo et al. (2013) & Governança corporativa e desempenho empresarial & Positivo \\
\hline $\begin{array}{l}\text { Rossoni e Machado-da- } \\
\text {-Silva (2013) }\end{array}$ & Governança corporativa e valor de mercado & Positivo \\
\hline Caixe e Krauter (2014) & Governança corporativa e valor de mercado & Positivo \\
\hline
\end{tabular}

Fonte: Elaborado pelos autores. 
Observa-se na Tabela 1 que a maioria dos resultados encontrados nos estudos empíricos anteriores reforça a hipótese de pesquisa levantada neste estudo. Os procedimentos metodológicos para testar a hipótese e atender ao objetivo da pesquisa são apresentados a seguir.

\section{Metodologia}

Quanto aos objetivos, a pesquisa classifica-se como descritiva, pois procura esclarecer determinadas características e aspectos inerentes (SAMPIERI; COLLADO; LÚCIO, 2013) à reputação do diretor-executivo, do acionista majoritário e da governança corporativa de empresas listadas na BM\&FBovespa. Quanto à natureza, trata-se de pesquisa quantitativa, haja vista que os dados e as evidências coletados podem ser quantificados, mensurados e preparados para ser submetidos a testes estatísticos (MARTINS; THEÓPHILO, 2009). Quanto aos procedimentos, caracteriza-se por ser de cunho documental, empregando fontes secundárias, ou seja, banco de dados, arquivos, relatórios e outros (MARTINS; THEÓPHILO, 2009).

A população da pesquisa compreende todas as 524 empresas listadas na BM\&FBovespa na posição de 22/11/2015. Por sua vez, a amostra reúne 230 empresas em que foi possível identificar todas as variáveis estudadas, além da exclusão de observações outliers por meio do teste bacon.

Para se obter a variável reputação corporativa (REP), utilizou-se a análise fatorial que, segundo Fávero et al. (2009, p. 235), “é uma técnica multivariada de interdependência que busca sintetizar as relações observadas entre um conjunto de variáveis inter-relacionadas, buscando identificar fatores comuns". Para tanto, utilizaram-se a reputação do acionista majoritário, a reputação do diretor-executivo e a governança corporativa na busca de gerar o fator comum 'reputação corporativa' (REP). Os dados necessários foram coletados no Formulário de Referência e nas Demonstrações Financeiras Padronizadas (Balanço Patrimonial), referentes ao exercício de 2013, disponíveis no website da BM\&FBovespa, além das informações consignadas no Estatuto Social, disponível no website institucional de cada empresa, e no ranking Proprietários do Brasil (INSTITUTO MAIS; EITA, 2014).

A identificação da reputação do acionista majoritário (RAM) 
utiliza o Índice de Poder Acumulado (IPA), do ranking Proprietários do Brasil, que demonstra o poder econômico de cada acionista (INSTITUTO MAIS; EITA, 2014). A proposta do ranking é que o poder de um acionista em determinada empresa está relacionado com a sua participação relativa. Além disso, esse poder deve estar relacionado com algum indicador que identifique o tamanho da empresa, que, no caso do ranking, considera-se a receita líquida da empresa. No caso de controle, todos os demais acionistas têm poder "zero". O poder acumulado é definido como a cascata recursiva de todas as participações diretas e indiretas do acionista, até o final da cadeia de participações (INSTITUTO MAIS; EITA, 2014). Para tanto, foi identificado o último proprietário de cada cadeia de empresas.

O índice de reputação do diretor-executivo (RDE) foi construído a partir de Niap e Taylor (2012), considerando-se quatro categorias:

(I) as qualificações do diretor-executivo: 1 = ensino médio ou inferior, 2 = grau de bacharel e 3 = pós-graduações;

(II) participação em conselhos: 1 = nenhuma, 2 = participação em outro conselho de administração, 3 = participação em mais de um conselho de administração;

(III) o mandato de diretor-executivo com a empresa no período: 1 = até dois anos, 2 = não mais de três anos, $3=$ mais de 3 anos; e

(IV) experiência prévia do diretor executivo: 1 = tinha experiência prévia de trabalho gerencial, mas não como um diretor/diretor executivo de qualquer empresa, 2 = tinha experiência de trabalho anterior como diretor/presidente de uma empresa não cotada, 3 = era um diretor ou diretor-executivo, ou ambos, de uma empresa listada em alguma bolsa. Todas as faixas de pontuação estão no intervalo de 1 a 3, para permitir a agregação. $\mathrm{O}$ índice de reputação foi, então, construído por meio da soma aritmética simples das pontuações do diretor executivo para as qualificações (i), participação em conselho (ii), mandato (iii) e experiência prévia (iv).

Por sua vez, o índice de governança corporativa (GOV) foi mensurado a partir das respostas a 15 questões baseadas no estudo de Lameira (2012), representativas da adoção de boas práticas de governança 
pelas empresas, divididas em cinco categorias: estrutura de propriedade e controle; nível de disclosure das informações e benefícios privados de controle; auditoria e conselho fiscal; conselho de administração e política de remuneração; e relacionamento com investidores.

Para atender ao objetivo geral - investigar a relação entre a reputação corporativa e a oportunidade de crescimento das empresas listadas na BM\&FBovespa -, aplica-se a regressão linear múltipla com erros robustos. Para tanto, utiliza-se a defasagem temporal entre a reputação corporativa e a oportunidade de crescimento; assim, as informações financeiras necessárias ao estudo se referem ao exercício findo em 31/12/2014 e foram levantadas no banco de dados Economatica ${ }^{\circledR}$. Para se testar a hipótese de pesquisa, o estudo envolve um modelo representado pela Equação 1:

$\mathrm{OPC}_{\mathrm{i}}=\beta_{0}+\beta_{1} \mathrm{REP}_{\mathrm{i}}+\beta_{2} \mathrm{ROA}_{\mathrm{i}}+\beta_{3} \mathrm{END}_{\mathrm{i}}+\beta_{4} \mathrm{CRE}_{\mathrm{i}}+\beta_{5} \mathrm{RIS}_{\mathrm{i}}+\beta_{6} \mathrm{TAM}_{\mathrm{i}}$ $+\varepsilon_{\mathrm{i}}$ (Equação 1)

A Tabela 2 apresenta as variáveis dependentes, independentes e de controle utilizadas na pesquisa.

Tabela 2 - Variáveis dependentes e independentes

\begin{tabular}{|c|c|c|c|c|c|}
\hline \multicolumn{2}{|l|}{ Variável } & Métrica & $\begin{array}{l}\text { Operacionali- } \\
\text { zação }\end{array}$ & $\begin{array}{l}\text { Fonte de } \\
\text { coleta }\end{array}$ & $\begin{array}{l}\text { Embasamento } \\
\text { teórico }\end{array}$ \\
\hline Dependente & OPC & $\begin{array}{l}\text { Oportuni- } \\
\text { dade de } \\
\text { crescimento }\end{array}$ & $\begin{array}{l}\text { Q de Tobin } \\
\text { ajustado }=(\text { Valor } \\
\text { de Mercado + } \\
(\text { Passivo Total - } \\
\text { Ativo Circulante } \\
+ \text { Estoques) }) / \\
\text { Ativo Total }\end{array}$ & Economatica ${ }^{\circledR}$ & $\begin{array}{l}\text { Fombrun e } \\
\text { Shanley (1990) } \\
\text { Chung e Pruitt } \\
\text { (1994) } \\
\text { Rose e Thomsen } \\
\text { (2004) } \\
\text { Cole (2012) }\end{array}$ \\
\hline $\begin{array}{l}\text { Indepen- } \\
\text { dente }\end{array}$ & REP & $\begin{array}{l}\text { Reputação } \\
\text { corporativa }\end{array}$ & $\begin{array}{l}\text { Fator(es) } \\
\text { obtido(s) por } \\
\text { meio da análise } \\
\text { fatorial com base } \\
\text { nas variáveis } \\
\text { RAM, RDE e } \\
\text { GOV }\end{array}$ & $\begin{array}{l}\text { Ranking } \\
\text { Proprietários } \\
\text { do Brasil, } \\
\text { Formulário } \\
\text { de Referên- } \\
\text { cia, Balanço } \\
\text { Patrimonial } \\
\text { e Estatuto } \\
\text { Social }\end{array}$ & $\begin{array}{l}\text { Robert e } \\
\text { Dowling (2002) } \\
\text { Musteen, Datta } \\
\text { e Kemmerer } \\
\text { (2010) } \\
\text { Niap e Taylor } \\
\text { (2012) } \\
\text { Lameira (2012) }\end{array}$ \\
\hline
\end{tabular}




\begin{tabular}{|c|c|c|c|c|c|}
\hline \multicolumn{2}{|l|}{ Variável } & Métrica & $\begin{array}{l}\text { Operacionali- } \\
\text { zação }\end{array}$ & $\begin{array}{l}\text { Fonte de } \\
\text { coleta }\end{array}$ & $\begin{array}{l}\text { Embasamento } \\
\text { teórico }\end{array}$ \\
\hline \multirow{5}{*}{ Controle } & ROA & $\begin{array}{l}\text { Desempe- } \\
\text { nho econô- } \\
\text { mico }\end{array}$ & $\begin{array}{l}\text { Lucro líquido / } \\
\text { ativo Total }\end{array}$ & Economatica $^{\circledR}$ & $\begin{array}{l}\text { Fombrun e } \\
\text { Shanley (1990) } \\
\text { Musteen, Datta } \\
\text { e Kemmerer } \\
(2010)\end{array}$ \\
\hline & END & $\begin{array}{l}\text { Endivida- } \\
\text { mento }\end{array}$ & $\begin{array}{l}\text { Passivo total / } \\
\text { Ativo total }\end{array}$ & Economatica $^{\circledR}$ & $\begin{array}{l}\text { Brammer, } \\
\text { Millington e } \\
\text { Pavelin (2009) } \\
\text { Rossoni e Ma- } \\
\text { chado-da-Silva } \\
\text { (2013) }\end{array}$ \\
\hline & CRE & $\begin{array}{l}\text { Crescimento } \\
\text { das vendas }\end{array}$ & $\begin{array}{l}\text { (Receita de Ven- } \\
\text { das }_{t}-\text { Receita de } \\
\left.\text { Vendas }_{t-1}\right) / \text { Recei- } \\
\text { ta de Vendas }\end{array}$ & Economatica $^{\circledR}$ & $\begin{array}{l}\text { Musteen, Datta } \\
\text { e Kemmerer } \\
(2010)\end{array}$ \\
\hline & RIS & $\begin{array}{l}\text { Risco de } \\
\text { mercado }\end{array}$ & $\begin{array}{l}\text { Coeficiente } \beta \text { do } \\
\text { CAPM }\end{array}$ & Economatica $^{\circledR}$ & $\begin{array}{l}\text { Fombrun e } \\
\text { Shanley (1990) } \\
\text { Musteen, Datta } \\
\text { e Kemmerer } \\
(2010)\end{array}$ \\
\hline & TAM & Tamanho & $\begin{array}{l}\text { Logaritmo } \\
\text { natural do Ativo } \\
\text { Total }\end{array}$ & Economatica $^{\circledR}$ & $\begin{array}{l}\text { Fombrun e } \\
\text { Shanley (1990) } \\
\text { Musteen, Datta } \\
\text { e Kemmerer } \\
(2010)\end{array}$ \\
\hline
\end{tabular}

Fonte: Elaborado pelos autores.

O tratamento dos dados (análise fatorial e regressão linear múltipla) foi realizado com o auxílio do aplicativo STATA, versão 13.

\section{Resultados dA PESQUiSA}

Primeiramente, procedeu-se à análise descritiva dos dados referentes à criação da variável reputação corporativa por meio da análise fatorial. Os dados das variáveis reputação do acionista majoritário (RAM), reputação do diretor-executivo (RDE) e governança corporativa (GOV) estão dispostos na Tabela 3. 
Tabela 3 - Estatística descritiva das variáveis que compõem a reputação corporativa

\begin{tabular}{l|l|l|l|l|l}
\hline Variáveis & Mínimo & Máximo & Média & $\begin{array}{l}\text { Desvio- } \\
\text { padrão }\end{array}$ & $\begin{array}{l}\text { Coeficiente } \\
\text { de Variação }\end{array}$ \\
\hline RAM & 0,00 & 0,08 & 0,00 & 0,01 & 2,35 \\
\hline RDE & 0,33 & 0,92 & 0,59 & 0,14 & 0,24 \\
\hline GOV & 0,13 & 0,93 & 0,55 & 0,18 & 0,33 \\
\hline
\end{tabular}

Fonte: Dados da pesquisa.

Na Tabela 3, é possível verificar que a reputação do acionista majoritário registra uma média baixa. Cabe destacar que a amostra do presente estudo inclui 158 empresas familiares e utilizou, para mensurar a reputação do acionista majoritário, o Índice de Poder Acumulado (IPA), do ranking Proprietários do Brasil, que demonstra o poder econômico de um acionista em determinada empresa, por meio de sua participação relativa no mercado. Logo, acionistas de empresas familiares tendem a apresentar um IPA baixo, pois, geralmente, fazem parte apenas do grupo empresarial da família. De acordo com o coeficiente de variação, registra-se alta dispersão, o que comprova a heterogeneidade da amostra, podendo ser justificada pelos diferentes tipos de identidade dos acionistas majoritários das empresas analisadas (estatal, estrangeira, familiar e institucional).

Em contraponto, observa-se que a reputação do diretor-executivo está distribuída uniformemente entre as empresas, sugerindo que elas procuram contratar gestores com níveis de escolaridade, sapiência e experiência profissional similares, embora essas qualificações ainda possam ser consideradas medianas. Na mesma linha, constata-se que as práticas de governança corporativa estão, também, distribuídas homogeneamente, porém as empresas registram índice médio de práticas de governança (pouco acima de 50\%). Em relação ao valor da empresa, nota-se que a amostra é bastante heterogênea.

Após a realização da estatística descritiva, realizou-se a análise fatorial, com a finalidade de criar uma variável intitulada reputação corporativa, que inclui aspectos de governança corporativa, conforme é observado no estudo de Rossoni e Machado-da-Silva (2013), além da reputação pessoal de gestores e de acionistas majoritários. A Tabela 4 apresenta o resultado da análise fatorial. 
Tabela 4 - Análise fatorial

\begin{tabular}{|c|c|c|c|c|c|c|}
\hline \multirow{2}{*}{ Componente } & \multicolumn{3}{|c|}{ Valores próprios iniciais } & \multicolumn{3}{|c|}{$\begin{array}{l}\text { Somas de extração de carrega- } \\
\text { mentos ao quadrado }\end{array}$} \\
\hline & Total & \% de variância & $\begin{array}{l}\text { \% cumu- } \\
\text { lativa }\end{array}$ & Total & $\begin{array}{l}\text { \% de vari- } \\
\text { ância }\end{array}$ & $\begin{array}{l}\text { \% cumu- } \\
\text { lativa }\end{array}$ \\
\hline 1 & 1,26 & 41,92 & 41,92 & 1,26 & 41,92 & 41,92 \\
\hline 2 & 0,90 & 30,13 & 72,05 & & & \\
\hline 3 & 0,84 & 27,95 & 100,00 & & & \\
\hline \multicolumn{4}{|c|}{ Medida Kaiser-Meyer-Olkin (KMO) } & \multicolumn{3}{|l|}{0,554} \\
\hline \multicolumn{4}{|c|}{ Teste de esfericidade de Bartlett } & \multicolumn{3}{|c|}{$13,10^{* * *}$} \\
\hline
\end{tabular}

Nota: $\left({ }^{* * *}\right)$ Significância de até $1 \%$.

Fonte: Dados da pesquisa.

A Tabela 4 mostra que a medida $\mathrm{KMO}$ é 0,554 , indicando que possivelmente será formado mais de um fator, uma vez que as variáveis não compartilham muitos fatores comuns. Já o teste de esfericidade de Bartlett foi significante a 1\%, indicando que é válida a análise fatorial. Dessa forma, verifica-se que foi formado apenas um único fator, o qual é intitulado reputação corporativa, com uma variância total explicada de $41,92 \%$.

Identificada a variável reputação corporativa (REP), procedeu-se com a análise descritiva de todas as variáveis que compõem a regressão linear múltipla. A Tabela 5 apresenta a análise descritiva de tais variáveis.

Tabela 5 - Estatística descritiva

\begin{tabular}{l|l|l|l|l|l}
\hline Variável & Mínimo & Máximo & Média & Desvio-padrão & Coeficiente de variação \\
\hline OPC & $-0,09$ & 6,64 & 1,12 & 0,88 & 0,79 \\
\hline REP & $-2,19$ & 8,13 & 0,18 & 1,35 & 7,44 \\
\hline ROA & $-0,32$ & 0,80 & 0,03 & 0,10 & 3,79 \\
\hline END & 0,01 & 3,15 & 0,64 & 0,37 & 0,58 \\
\hline CRE & $-2,42$ & 1,56 & $-0,07$ & 0,30 & $-4,51$ \\
\hline RIS & $-2,75$ & 4,17 & 0,84 & 0,61 & 0,72 \\
\hline TAM & 8,84 & 19,59 & 1,38 & 1,68 & 1,21 \\
\hline
\end{tabular}

Fonte: Dados da pesquisa. 
Observando o coeficiente de variação, nota-se que há heterogeneidade entre as empresas em estudo. Isso pode ser devido às características reputacionais que geram diferenças entre as empresas, especialmente entre aquelas que competem no mesmo setor, sendo perceptível na variável reputação que apresenta maior coeficiente de variação. Em média, as empresas do estudo revelam oportunidade de crescimento, indicando que a utilização de ativos intangíveis não mensuráveis, entre eles a reputação, gera maior valor para as empresas. Outro ponto relevante é que mesmo em meio a um menor crescimento, levando-se em conta as vendas, as empresas conseguiram, em média, produzir um retorno operacional positivo. Quanto ao endividamento, elas possuem em torno de $64 \%$ dos seus ativos financiados por dívidas, indicando a estratégia utilizada pela empresa, conforme dispõem as teorias Trade-off e Pecking Order. Por sua vez, as empresas da amostra, em média, são consideradas de baixo risco, já que o coeficiente $\beta$ é inferior a um, e as empresas são consideradas de grande porte, pois o ativo total, em média, é de $\mathrm{R} \$ 4.585 .054,40$.

Antes de realizar a regressão linear múltipla, procedeu-se com a correlação de Pearson com o intuito de verificar as primeiras relações entre as variáveis do estudo. A Tabela 6 apresenta os resultados da Correlação de Pearson.

Tabela 6 - Correlação de Pearson

\begin{tabular}{l|l|l|l|l|l|l|l}
\hline & OPC & REP & ROA & END & CRE & RIS & TAM \\
\hline OPC & 1,00 & & & & & & \\
\hline REP & 0,05 & 1,00 & & & & & \\
\hline ROA & $0,52^{* * *}$ & 0,04 & 1,00 & & & & \\
\hline END & 0,07 & $-0,13^{* *}$ & $-0,43^{* * *}$ & 1,00 & & & \\
\hline CRE & 0,10 & 0,01 & 0,06 & $-0,07$ & 1,00 & & \\
\hline RIS & $-0,10$ & 0,00 & $-0,11^{*}$ & 0,08 & $-0,05$ & 1,00 & \\
\hline TAM & $-0,07$ & $0,46^{* * *}$ & 0,06 & $-0,14^{* *}$ & 0,02 & 0,04 & 1,00 \\
\hline
\end{tabular}

Nota: $\left({ }^{* *}\right)$ Significância de até $1 \% ;\left(^{* *}\right)$ Significância de até $5 \%$; $\left(^{*}\right)$ Significância de até $10 \%$.

Fonte: Dados da pesquisa. 
Com base nos dados da Tabela 6, verifica-se que a reputação corporativa (REP) e a oportunidade de crescimento (OPC) não estão correlacionadas; apenas pode-se observar uma relação positiva. Desse modo, individualmente, a reputação corporativa não teria a capacidade de gerar oportunidade de crescimento e, portanto, vantagem competitiva.

Dentre as variáveis de controle, apenas o desempenho (ROA) possui correlação positiva com a oportunidade de crescimento (OPC). Outras relações podem ser verificadas: endividamento (END) e tamanho (TAM) com reputação corporativa (REP), em que há uma correlação negativa e positiva, respectivamente; endividamento (END) e risco (RIS) com desempenho (ROA), no qual há uma correlação negativa e positiva, respectivamente; e uma correlação negativa entre endividamento (END) e tamanho (TAM).

Por último, realizou-se a regressão linear múltipla com erros robustos com o intuito de atender ao objetivo e assim rejeitar ou não a hipótese $\mathrm{H}_{1}$ (há relação positiva entre a reputação corporativa e a oportunidade de crescimento das empresas) de pesquisa. A Tabela 7 apresenta o resultado da regressão linear múltipla.

Tabela 7 - Resultados da regressão linear múltipla

\begin{tabular}{l|l|l|l|l}
\hline \multicolumn{2}{l}{ Variável } & \multicolumn{2}{c}{ Coeficiente } & \multicolumn{2}{l}{$\begin{array}{l}\text { Erro padrão } \\
\text { robusto }\end{array}$} & VIF \\
\hline Reputação corporativa & REP & $0,08^{* *}$ & 0,04 & 1,28 \\
\hline Desempenho empresarial & ROA & $5,79^{* * *}$ & 0,91 & 1,24 \\
\hline Endividamento & END & $0,86^{* * *}$ & 0,17 & 1,25 \\
\hline Crescimento nas vendas & CRE & $0,24^{* *}$ & 0,11 & 1,01 \\
\hline Risco de mercado & RIS & $-0,07$ & 0,06 & 1,02 \\
\hline Tamanho & TAM & $-0,06^{*}$ & 0,03 & 1,28 \\
\hline Constante & $1,32^{* *}$ & 0,54 & \\
\hline Teste F & $24,02^{* * *}$ & $\mathbf{R}^{\mathbf{2}}$ & 0,39 \\
\hline
\end{tabular}

Nota: ("*) Significância de até 1\%; (") Significância de até 5\%; (") Significância de até $10 \%$.

Fonte: Dados da pesquisa.

Observa-se, com base no $\mathrm{R}^{2}$, que o poder explicativo do modelo é baixo $(39 \%)$, além de significante até $1 \%$, ratificando a validade 
do modelo, já que esse resultado avalia a significância conjunta das variáveis explicativas.

Analisando-se os valores das variáveis independentes, pode-se concluir que todas as variáveis independentes influenciam a oportunidade de crescimento das empresas pesquisadas, neste estudo representado pelo $Q$ de Tobin ajustado. Verifica-se que a reputação corporativa, o desempenho empresarial, o endividamento e o crescimento nas vendas possuem relação positiva com a oportunidade de crescimento, já o tamanho se apresenta de forma inversa, haja vista que o coeficiente é negativo.

Logo, verifica-se que, considerando um nível de significância de até $10 \%$, o modelo de regressão indica que, no contexto das empresas listadas na BM\&FBovespa, quanto maior for a reputação corporativa, o desempenho empresarial, o endividamento e o crescimento nas vendas e menor for o tamanho das empresas, maior será a oportunidade de crescimento. Esse resultado sinaliza para a não rejeição da hipótese $\mathrm{H}_{1}$.

A relação positiva entre a oportunidade de crescimento e a reputação corporativa, que inclui a dimensão governança corporativa, mostrou-se significante no presente estudo, corroborando os estudos realizados por Caixe e Krauter (2014), Fombrun e Shanley (1990), Macedo e Corrar (2012), Melo et al. (2013), Men (2012), Niap e Taylor (2012), Lee e Roh (2012) e Rossoni e Machado-da-Silva (2013). Enquanto isso, o estudo de Caixeta et al. (2011) identificou uma influência negativa da reputação corporativa sobre o desempenho empresarial, e o estudo de Rose e Thomsen (2004) verificou que a reputação corporativa não influencia o valor de mercado da empresa. Levando em conta a governança na constituição da reputação corporativa, o presente estudo se diferencia ainda, dos achados de Batistella et al. (2004), em que se constatou que um melhor nível de governança corporativa não proporciona uma elevação significativa no desempenho empresarial.

\section{ConClusões}

A presente pesquisa teve como objetivo geral investigar a relação entre a reputação corporativa e a oportunidade de crescimento de 230 empresas listadas na BM\&FBovespa. 
De forma geral, verificou-se que as práticas de governança corporativa estão distribuídas homogeneamente, embora as empresas registrem índice médio de práticas de governança. Em relação à reputação do diretor-executivo, as empresas procuram contratar gestores com qualificações similares, estando essas qualificações abaixo da média, segundo o critério utilizado no estudo. Constatou-se, também, que a reputação do acionista majoritário se encontra abaixo da média, em decorrência da forte presença de empresas familiares na amostra. Essas variáveis formaram um fator intitulado reputação corporativa, aplicando-se a análise fatorial.

Por meio da regressão linear múltipla, verificou-se que todas as variáveis independente e de controle, com exceção da variável risco de mercado, influenciam a oportunidade de crescimento das empresas. Com base nos resultados encontrados, não foi possível rejeitar a hipótese $\mathrm{H}_{1}$ (há relação positiva entre a reputação corporativa e a oportunidade de crescimento das empresas) de pesquisa.

Ressalta-se que a reputação, pessoal ou corporativa, é um ativo que as empresas conseguem junto aos seus stakeholders e tem como características o diferencial competitivo, a vantagem competitiva, a oportunidade de crescimento, a maximização do valor da empresa e a redução de assimetria informacional e risco, além de atenuar os incentivos para um comportamento oportunístico e reduzir os custos de transação associados à racionalidade limitada (YOON; GUFFEY; KIJEWSKI, 1993; CHILES; MCMACKIN, 1996; BROMLEY, 2001; ROBERTS; DOWLING, 2002; ZABALA et al., 2005; BALMER; GREYSER, 2006; THOMAZ; BRITO, 2010).

Assim, com base na redução dos preceitos da ECT (racionalidade limitada e comportamento oportunístico), os acionistas majoritários e diretores-executivos com melhor reputação, em empresas com boa governança corporativa, tendem a não adotar comportamento oportunístico e assim reduzem os custos de transação, que desencadeiam em oportunidade de crescimento e maximização do valor das empresas, uma vez que elas se legitimam no mercado e constroem sua reputação. Sob essa perspectiva, os resultados da pesquisa procuram contribuir para o melhor entendimento da relação entre reputação (pessoal ou corporativa), governança corporativa e 
oportunidade de crescimento, visando à expansão do conhecimento e referências para novas pesquisas.

Entre as limitações do estudo, destacam-se a composição da amostra, que considera apenas empresas listadas na bolsa brasileira, e o período de análise, que compreendeu apenas um exercício social, embora se utilize o critério da defasagem temporal. Destarte, para novas pesquisas sugerem-se a ampliação do período de análise e a utilização de uma amostra que contemple empresas de outros países ou listadas em bolsas estrangeiras. Além disso, recomenda-se ainda a utilização de variáveis de desempenho que exprimam a criação de valor, bem como a análise da relação dos construtos reputação e governança corporativa sob a abordagem de outras teorias, como a Teoria da Sinalização.

\section{REFERÊNCIAS}

ALMEIDA, R. S.; KLOTZLE, M. C.; PINTO, A. C. F. Composição do conselho de administração no setor de entrega de energia elétrica do Brasil. Revista de Administração da UNIMEP, v. 11, n. 1, p. 156-180, 2013.

ALSOP, R. J. The 18 immutable laws of corporate reputation: Creating, protecting and repairing your most valuable asset. London: Kogan Page Publishers, 2006.

ANDRADE, L. P.; SALAZAR, G. T.; CALEGARIO, C. L. L.; SILVA, S. S. Governança corporativa: Uma análise da relação do conselho de administração com o valor de mercado e desempenho das empresas brasileiras. RAM - Revista de Administração Mackenzie, v. 10, n. 4, p. 4-31, 2009.

AZEVEDO, P. F. Nova economia institucional: referencial geral e aplicações para a agricultura. Agricultura em São Paulo, v. 47, n. 1, p. 33-52, 2000.

BALMER, J. M. T; GREYSER, S. A. Corporate marketing: Integrating corporate identity, corporate branding, corporate communications, corporate image and corporate reputation. European Journal of Marketing, v. 40, n. 7/8, p. 730-741, 2006.

BATISTELLA, F. D.; CORRAR, L. J.; BERGMANN, D. R.; AGUIAR, A. D. Retornos de ações e governança corporativa: um estudo de eventos. In: CONGRESSO UPS DE CONTROLADORIA E CONTABILIDADE, 4., 2004, São Paulo. Anais... São Paulo: FEA/USP, 2004.

BERGH, D. D.; KETCHEN, D. J.; BOYD, B. K.; BERGH, J. New frontiers of the reputation Performance relationship: Insights from multiple theories. Journal of Management, v. 36, n. 3, p. 620-632, 2010.

BRAMMER, S.; MILLINGTON, A.; PAVELI, S. Corporate reputation and women on the board. British Journal of Management, v. 20, n. 1, p. 17-29, 2009. 
BRITO, L. A. L.; VASCONCELOS, F. C. A heterogeneidade do desempenho, suas causas e o conceito de vantagem competitiva: Proposta de uma métrica. RAC - Revista de Administração Contemporânea, v. 8, n. especial, p. 107-129, 2004.

BROMLEY, D. B. Relationships between personal and corporate reputation. European Journal of Marketing, v. 35, n. 3/4, p. 316-334, 2001.

CAIXE, D. F.; MATIAS, A. B.; OLIVEIRA, S. V. W. B. Free float e valor de mercado corporativo: Um estudo do período de 2001 a 2010. Revista Organizações \& Sociedade, v. 20, n. 67, p. 733-751, 2013.

CAIXE, D. F.; KRAUTER, E. Relação entre governança corporativa e valor de mercado: mitigando problemas de endogeneidade. BBR - Brazilian Business Review, v. 11, n. 1, p. 96-117, 2014.

CAIXETA, C. G. F.; LOPES, H. E. G.; BERNARDES, P.; CARDOSO, M. B. R.;

CAMPOS, T. L. C. Estrutura de propriedade e desempenho econômico: Uma avaliação empírica para as empresas de capital aberto no Brasil. RAUSP - Revista de Administração USP, v. 41, n. 4, p. 369-380, 2006.

CASTRO, D. J. D. Como se constrói uma reputação corporativa? 2008. 170 f. Dissertação (Mestrado em Administração de Empresas) - Escola de Administração de Empresas de São Paulo da Fundação Getúlio Vargas, São Paulo, 2008.

CHILES, T.; MCMACKIN, J. Integrating variable risk preferences, trust, and transaction cost economics. Academy of Management Review, v. 21, n. 1, p. 73-99, 1996.

CHUNG, K. H; PRUITT, S. W. A simple approximation of Tobin's q. Financial Management, v. 23, n. 3, p. 70-74, 1994.

COLE, S. The impact of reputation on market value. World Economics, v. 13, n. 3, p. 47-68, 2012.

CRUZ, C. V. O. A.; LIMA, G. A. S. F. Reputação corporativa e nível de disclosure das empresas de capital aberto no Brasil. Revista Universo Contábil, v. 6, n. 1, p. 85-101, 2010.

CUNHA, M. F.; IARA, R. N.; RECH, I. J. O valor da perpetuidade na avaliação de empresas no Brasil. Revista de Contabilidade e Organizações, v. 8, n. 20, p. 17-21, 2014.

FÁVERO, L. P.; BELFIORE, P.; SILVA, F. L; CHAN, B. L. Análise de dados: modelagem multivariada para tomada de decisões. Rio de Janeiro: Elsevier, 2009.

FICH, E. M.; SHIVDASANI, A. Financial fraud, director reputation, and shareholder wealth. Journal of Financial Economics, v. 86, n. 2, p. 306-336, 2007.

FOMBRUN, C.; SHANLEY, M. What's in a name? Reputation building and corporate strategy. Academy of Management Journal, v. 33, n. 2, p. 233-258, 1990.

FOMBRUN, C.; VAN RIEL, C. B. M. Fame and Fortune: how successful companies build winning reputations. Upper Saddle River: Prentice Hall, 2004.

IBGC - Instituto Brasileiro de Governança Corporativa. Código brasileiro das melhores práticas de governança corporativa. 3. ed. São Paulo: IBGC, 2009. Disponível em: <http:// www.ibgc.org.br/CodigoMelhoresPraticas.aspx>. Acesso em: 23 mar. 2014. 
INSTITUTO MAIS; EITA. Quem são os proprietários do Brasil? Disponível em: <http://www. proprietariosdobrasil.org.br/index.php/pt-br/>. Acesso em: 09 maio 2014.

KAPPLER, L.; LOVE, I. Corporate governance, investor protection, and performance in emerging markets. Working Paper 2.818. World Bank Policy Research, 2002.

KARUNA, C. CEO reputation and internal corporate governance. Working paper. The Paul Merage School of Business, University of California at Irvine, 2009.

LA PORTA, R.; LOPEZ-DE-SILANES, F.; SHLEIFER, A.; VISHNY, R. W. Law and Finance. Journal of Political Economy, n. 106, n. 6, p. 1113-1155, 1998.

LA PORTA, R.; LOPEZ-DE-SILANES, F.; SHLEIFER, A. Corporate ownership around the world. The Journal of Finance, v. 54, n. 2, p. 471-517, 1999.

LAIRD, M. D.; ZBOJA J. J.; MARTINEZ A. D.; FERRIS, G. R. Performance and political skill in personal reputation assessments. Journal of Managerial Psychology, v. 28, n. 6, p. 661676, 2013.

LAMEIRA, V. J. As relações entre governança e risco nas companhias abertas brasileiras. Revista Brasileira de Gestão de Negócios, v. 14, n. 42, p. 7-25, 2012.

LEE, J.; ROH, J. J. Revisiting corporate reputation and firm performance link. Benchmarking: An International Journal, v. 19, n. 4, p. 649-664, 2012.

MACEDO, M. A. S.; CORRAR, L. J. Análise comparativa do desempenho contábil-financeiro de empresas com boas práticas de governança corporativa no Brasil. RC\&C - Revista Contabilidade e Controladoria, v. 4, n. 1, p. 42-61, 2012.

MACHADO FILHO, C. A. P.; ZYLBERSZTAJN, D. Capital Reputação e Responsabilidade Social: Considerações Teóricas. Caderno de Pesquisas em Administração, v. 11, n. 2, p. 8798, 2004.

MAIA, A. B. G. R.; VASCONCELOS, A. C.; LUCA, M. M. M. Governança corporativa e internacionalização do capital social das companhias brasileiras do setor de construção e transportes. InternexT - Revista Eletrônica de Negócios Internacionais da ESPM, v. 8, n. 2, p. 40-60, 2013.

MARTINS, G. R.; THEÓPHILO, C. R. Metodologia da investigação científica para ciências sociais aplicadas. 2. ed. São Paulo: Atlas, 2009.

MELO, R. S.; BATISTA, P. C. S.; MACEDO, A. C. M.; COSTA, R. B. L. A contribuição da governança corporativa para o desempenho das empresas brasileiras de capital aberto. REGE - Revista de Gestão, v. 20, n. 1, p. 79-92, 2013.

MEN, L. R. CEO credibility, perceived organizational reputation, and employee engagement. Public Relations Review, v. 38, n. 1, p. 171-173, 2012.

MUSTEEN, M.; DATTA, D. K.; KEMMERER, B. Corporate reputation: Do board characteristic matter? British Journal of Management, v. 21, n. 2, p. 498-510, 2010.

NIAP, D. T. F.; TAYLOR, D. CEO Personal Reputation: does it affect remuneration during times of economic turbulence? Procedia Economics and Finance, v. 2, n. 1, p. 125-134, 2012. 
OKIMURA, R. T. Estrutura de propriedade, governança corporativa, valor e desempenho das empresas no Brasil. 132 f. Dissertação (Mestrado em Administração) - Programa de Pós-Graduação em Administração, Universidade de São Paulo, São Paulo, 2003.

OLIVEIRA, M. C.; PONTE, V. M. R.; LUCA, M. M. M.; OLIVEIRA, O. V.; ARAGÃO, L. A.; GELEILATE, J. M. G. Práticas de governança corporativa adotadas por companhias fechadas brasileiras e alinhamento às demandas do mercado de capitais. BASE - Revista de Administração e Contabilidade da UNISINOS, v. 10, n. 3, p. 196-209, 2013.

PEIXE, F. C. D. Novo mercado: obstáculos e atrativos para as empresas do nível 1 de governança corporativa. 98 f. Dissertação (Mestrado em Administração) - Programa de Pós-Graduação em Administração, Universidade de São Paulo, São Paulo, 2003.

PERES, U. D. Custos de transação e estrutura de governança no setor público. Revista Brasileira de Gestão de Negócios, v. 9, n. 24, p. 15-30, 2007.

ROBERTS, P. W.; DOWLING, G. R. Corporate reputation and sustained superior financial performance. Strategic Management Journal, v. 23, n. 12, p. 1077-1093, 2002.

ROSE, C.; THOMSEN, S. The impact of corporate reputation on performance: some Danish evidence. European Management Journal, v. 22, n. 2, p. 201-210, 2004.

ROSSONI, L.; SILVA, C. M. da. Legitimidade, governança corporativa e desempenho: análise das empresas da BM\&FBOVESPA. RAE - Revista de Administração de Empresas, v. 53, n. 3, p. 272-289, 2013.

SAMPIERI, R. H.; COLLADO, C. F.; LÚCIO, P. B. Metodologia de pesquisa. 3. ed. São Paulo: McGraw Hill, 2013.

SILVA JÚNIOR, A.; SILVA, P. O. M.; SILVA, A. R. L. Sistemas de valores e implicações na governança corporativa em um grupo empresarial familiar. Revista Organizações e Sociedade, v. 20, n. 65, p. 239-260, 2013.

SILVEIRA, A. D. M. Governança corporativa, desempenho e valor da empresa no Brasil. 152 f. Dissertação (Mestrado em Administração) - Programa de Pós-Graduação em Administração, Universidade de São Paulo, São Paulo, 2002.

SILVEIRA, A. D. M.; BARROS. L.; A.; B.; C.; FAMÁ, R. Estrutura de Governança e Desempenho Financeiro nas Companhias Abertas Brasileiras: Um Estudo Empírico. Caderno de Pesquisas em Administração, v. 10, n. 1, p. 57-71 2003.

SILVEIRA, A. D. M. Governança corporativa e estrutura de propriedade: determinantes e relação com o desempenho das empresas no Brasil. 250 f. Tese (Doutorado em Administração) - Programa de Pós-Graduação em Administração, Universidade de São Paulo, São Paulo, 2004.

SILVEIRA, A. D. M.; LEAL, R. P. C.; BARROS, L. A. B. C.; SILVA, A. L. C. Endogeneity of Brazilian corporate governance quality determinants. Corporate Governance, v. 10, n. 2, p. 191-202, 2010.

SOARES, C. A relação entre fatores macroeconômicos e governança corporativa com o comportamento do mercado de capitais brasileiro. $178 \mathrm{f}$. Dissertação (Mestrado em Contabilidade) - Programa de Mestrado em Contabilidade, Universidade Federal do Paraná, Curitiba, 2008. 
THOMAZ, J. C.; BRITO, E. P. Z. Reputação corporativa: construtos formativos e implicações para a gestão. Revista de Administração Contemporânea, v. 14, n. 2, p. 229-250, 2010. THOMSEN, S.; PEDERSEN, T. Ownership structure and economics performance in the European companies. Strategic Management Journal, v. 21, n. 6, p. 625-705, 2000.

VAN RIEL, C. B. M.; FOMBRUN, C. J. Essentials of corporate communications. New York: Routledge, 2007.

WILLIAMSON, O. E. The mechanisms of governance. New York: Oxford University Press, 1996.

YOON, E.; GUFFEY, H. J.; KIJEWSKI, V. The effects of information and company reputation on intentions to buy a business service. Journal of Business Research, v. 27, p. 215-228, 1993.

ZABALA, I.; PANADERO, G.; GALLARDO, L. M.; AMATE, C. M.; SÁNCHEZ-GALINDO, M.; TENA, I.; VILLALBA, I. Corporate reputation in professional services firms: reputation management based on intellectual capital management. Corporate Reputation Review, v. 8, n. 1, p. 59-71, 2005.

Recebido em: 30-01-2017

Aprovado em: 26-04-2017

Avaliado pelo sistema double blind review.

Editor: Elmo Tambosi Filho

Disponível em http://mjs.metodista.br/index.php/roc 